\title{
CAVEIRÃO \& HOMEM PROSTITUTO \& LATE QUE EU ESTOU PASSANDO 0 QUE VEMOS, 0 QUE NOS OLHA NO COTIDIANO ESCOLAR
}

Aldo Victorio Filho

Aristóteles Berino

Aborda a 'funkificação' das escolas: agenciamentos juvenis que desestabilizam o governo escolar, minam os espaços de rotina e de ordem estabelecida, confrontando as práticas institucionalizadas de cálculo e previsibilidade do cotidiano e desmoralizando o imaginário e as narrativas estabelecidas na modernidade a respeito da diligência pedagógica - ao som do batidão. [Abstract on page 247]

ESTÉtICA E CULTURAS POPULARES, JUVENTUDES, FUNK. 
Para pensar a linguagem é preciso penetrar na fala da linguagem a fim de conseguirmos morar na linguagem, isto é, na sua fala e não na nossa. (HEIDEGGER, 2003, p. 9)

\section{CORPOS INVESTIGATIVOS}

$\mathrm{O}$ ato investigativo se faz com a prontidão e o funcionamento de nossos órgãos, pele ativa como a dos tubarões, captação de centelhas de sentido, radares para a beleza e, sobretudo, atenção à continuidade da derme coletiva. Assim se realizam perceptos e afectos. Mostrar nossos caminhos em direção ao que amamos é uma das mais preciosas maneiras de teorizar. Sabendo que a percepção desses caminhos é criação estética, elucidá-los também o é.

A aventura intelectual a que nos propomos se nos afigura de tal modo desertora em relação à maioria dos regimes que nos formaram, que nos faz pensá-la mais como um fluxo de potência avizinhado à poesia do que uma intenção de atualização das formalidades escriturísticas acadêmicas.

Assim, aquilo que em uma visada convencional seria identificado como o objeto de nosso estudo impõe-se a nós como escolha e adesão estética. E como tal reposiciona escolhas e adesões anteriores. A escolha da educação como área de formação e campo de atuação profissional e de pesquisa é, assim, ressignificada como escolha já estética.

Ao longo do artigo, cuja centralidade é ocupada pelo que denominamos funkificação das escolas, investiremos na explicitação de nossa proposta de deslocamento investigativo, dirigindo nossos perceptos ao epicentro do que queremos tratar. Nossos corpos investigativos, com todos os nossos órgãos vitais, pele e sentidos, fundem-se assim com os afectos que nos atingem e envolvem. Expor nossa movimentação em relação ao que estudamos parece-nos, portanto, o único caminho para o propósito dessa empreitada, ou seja, destacar, ainda e cada vez mais, certa sintonia juvenil usurpada de sua existencialidade por representações generalistas e generalizantes; destacá-la como manancial de criação de sua própria fala, que em seu sentido mais agudo é vital a sua própria visibilidade - em outros termos, vital a sua culminância humana.

Entendemos que presentificar uma esfera social - neste caso, 'certa' juventude periferizada - é uma das realizações imperiosas de nossa ação acadêmica e, necessariamente, política. Lembramos, então, que a organização social vigente, por mais caótica que seja representada ou por menos conformável às matrizes explicativas que as contenha, pressupõe e, de muitas formas, impõe perversa diagramação dos territórios simbólicos. Assim, alguns estarão representados, por menos verossímeis e suportáveis que sejam tais representações, em nichos conceituais que arrastam uma série de identificações sintéticas, enquanto outros sequer figuraram em nichos identificadores que lhes sejam minimamente leais em relação a suas potências e produções, pois estes últimos sempre transbordam as etiquetações praticadas. Sobram socialmente, sobram nas cidades, nas filas de emprego. Lotam as turmas de aceleração escolar, os trens, e abarrotam as penitenciárias. Dessa forma povoam o imaginário da tensão civilidade versus barbárie e 
ameaçam, em sua invisibilidade e apreensão, a ordem e a alvura das instituições que se creem mantidas e intactas na cidade espatifada.

Entretanto, não é sob tais signos, de significação rota pelo excessivo e improdutivo uso, que desejamos fazê-los emergir em nossa fala. Nem aventamos um outro lado do mal. Nosso empenho é não os arremessar mais longe ainda desse fórum que nos propomos instaurar por sua denominação (BLANCHOT, 2005, p. 45). Portanto, falamos de nós. E na energia que faz circular e desdobrar-se nosso pensamento, não negaremos a presença flagrante desses jovens que, inassujeitáveis a nossas palavras/representações, se apresentam via sua produção de fala. Em sua mais potente possibilidade, que é inegavelmente a criação estética na sedutora matéria plástica do verbo. Criação realizada no que compreendemos como poesia funk e que percorre, original, para além das idealizações enclausuradoras dos termos pureza ou mistura, o corpo de nossa fala, nossa voz, nosso corpo de professor colonizado pela beleza de nossos alunos.

\section{POESIAS-CORPOS}

Caveirão brotou no morro / Querendo aterrorizar / Manda o caveirão embora / Que a galera quer dançar / Se o caveirão não for / O bicho vai pegar / Se mexer com o Comando / Vai tomar só de AK / Vai / tô de olho no caveirão Vai / tô de olho no caveirão // Mexeu com o Comando / Comando se embola / E o que que ele faz? / Manda bala (“Caveirão”, Mc Didô).

Eu tô com várias mulher! / E pra aquelas mulher que não sabem o que que é um homem prostituto / Um homem prostituto é aquele homem que sai com várias / Várias mulheres / Naquele pique, tipo assim / Na segunda tô com a Carla / Na terça tô com Cristina / Quarta-feira com a Carol / Quinta-feira com a Marina / Sexta-feira tô com a Bruna / No sábado tô com Vera / E no domingo eu tô com todas elas (2x) // É prostituto, é prostituto (3x) / De carteira assinada e tudo (2x) // Mas tem mina por aí que andam batendo neurose / Dizendo que a nossa fama não é aquelas das melhores / Só porque elas vem pro baile e viram duas mulheres saindo comigo / Agora ela quer explanar dizendo que eu tô me prostituindo // É prostituto, é prostituto (3x) / De carteira assinada tudo (2x) (“Prostituto", Mc Buiu).

Ôô coringa, seu otário para de vacilação. / Tu é pouca areia pro meu caminhão! / Agora é diferente, somos nós / Mulheres que estamos mandando / Fica de quatro, balança o rabo, me dá a patinha, bota a linguinha pra fora / e late, late seu cachorro.. late que eu tô passando! // Late, late... late que eu tô passando vem // Late, late.. dá patinha, vai vem! / Late, late.. late que eu tô passando vai / Late, late... // No passado me esnobava, / agora tá me cantando / Seu comédia, seu xarope / Agora late que eu tô passando vai // Late late... late que eu tô passando vem / Late, late.. dá patinha, vai vem! / Late, late.. late que eu tô passando vai / Late, late...toma ração, toma ração vem!! // Me chamava de magrela / Vivia me esculachando / Seu cordão é uma coleira / Vem cachorro eu tô chamando // Então.. late, late.. late que eu tô passando vem / Late, late...toma ração, toma ração vem!! / Late, late.. late que eu tô passan- 
do vai / Late! fica de quatro.. toma, toma, toma.. toma / Cachorrinho, toma! // Gaiola das popozudas não aceita palhaçada / Se o cara é abusado, nós metemos a porrada / Ele tomou uma coça, mas não tá adiantando / Da ração pra esse otário / Agora late que eu tô passando // Vai.. late, late.. late que eu tô passando vem / Late, late... dá patinha, vai vem! / Late, late... late que eu tô passando vai / Late, late.. toma ração, toma ração.. vem! ("Late que eu tô passando", Gaiola das Popozudas).

\section{FISICALIDADES}

Então, o desafio: o que nós vemos é o que nos olha. Retomamos essa frase, parte do título deste trabalho e, antes, título de obra de Didier-Huberman (1998) ${ }^{1}$, cuja for-

1. re.gar.der: vt+vi 1 fitar, olhar. 2 reparar, observar, examinar. 3 tocar, dizer respeito a. vpr 4 olhar-se. regarder de travers olhar atravessado. regarder du coin de l'oeil ou par en dessous olhar de soslaio. regarder un film assistir a um filme. ma original, em francês, também significa: o que vemos é o que nos diz respeito. Assim, acatamos que nossa percepção é afinada com aquilo que nos dispomos a ver. Redução drástica, sem dúvida, mas também desafiadora posto que nos impõe o enfrentamento das condições que norteiam o olhar, neste caso, sobre a escola. Ao menos faz investir na leitura do que nos faz ver o que vemos.

Não há, na verdade, novidade nesta proposta. Entretanto, convém sempre repeti-la, pois nos parece que uma das forças de manutenção da educação - como esta se tem desdobrado - seria justamente a rigidez das certezas investigativas, aliada à indulgência na elucidação das redes que fazem ver o que veem aqueles que pretendem discuti-la, traduzi-la, etc. Em outras palavras, reivindicamos nossa participação no panorama investigado. Seja via o reconhecimento da fisicalidade de nossa presença ou nossa não menos forte presença simbólica, via a escolha do que pretendemos tratar. O que nos leva ao funk cantado, dançado e vivido em muitas dimensões por alunos e alunas, o que nos faz olhar e ver o funk enunciador das vidas desses meninos e meninas é o mesmo impulso que nos coloca no time/tempo da atividade intelectual que vivemos e conduz nossos modos de viver o engajamento das práticas docentes.

Reconhecer a população juvenil, certamente majoritária, das escolas sob esse viés é, não menos certamente, reconhecer a vitalidade de sua potência autoenunciadora. Força que colide com as lentes que focam seus produtores como massa desqualificada. Apatia, desinteresse, indisciplina, improdutividade são termos aos quais se recorre, frequentemente, na incômoda incompreensão do que se vê. A desqualificação juvenil grava-se, sobretudo, quando o que é visto tem sua leitura interrompida na superfície dos corpos olhados e quando essa interrupção é provocada pela radical intolerância à diferença. Patologia decorrente das redes ainda fortemente ligadas ao passado/presente escravagista que urdiu nossa injusta sociedade. Redes alicerçadas pela moralidade cristã em uso frequente nas artimanhas do mercado de coisas e de gentes, no qual uns são tomados pelos outros ao sabor dos interesses dos que controlam a cidade. Tal aspecto não é diferente das lógicas e práticas aplicadas às instâncias públicas, como em nosso cam- 
po, a educação. É preciso enfatizar, então, que a maquinaria moralista a que aludimos moldou ao longo de nossa breve história brasileira seus aparatos e perfis para selecionar em tempo cada vez menor o que vale e o que não vale para a produção a serviço da qual está tal equipamento.

\section{REALIZAÇÕES-FABULAÇÕES}

Não faz muito tempo lecionávamos também na educação básica. Até o início de 2006. Aldo na rede pública estadual do Rio de Janeiro, com suas turmas do ensino médio. Aristóteles na rede pública municipal, na cidade do Rio de Janeiro, com suas turmas de quinta à oitava série. Algumas circunstâncias profissionais, em um caso, e o regime de dedicação exclusiva, em outro, nos fizeram deixar esse nível de ensino. Trata-se, entretanto, de abandono apenas relativo, já que continuamos visitando nossas experiências anteriores, uma vez que o trabalho na formação de professores é uma continuação de nossas histórias de vida com a educação e, particularmente, porque a escola pública e os jovens permaneceram no coração de nossas investidas como trabalhadores culturais e intelectuais públicos (GIROUX. 1999, p; 280). A criação do Grupo de Pesquisa Estudos Culturais em Educação e Arte, em 2007, de caráter interinstitucional (UFRRJ/Uerj/Unifap), faz parte desse desvelo, abrigando nosso interesse pelas juvenilidades. Destacamos também nossa presença no Laboratório de Educação e Imagem, do ProPed, na Uerj, participando dos grupos de pesquisa dirigidos pelas professoras Inês Barbosa de Oliveira e Nilda Alves, discutindo o cotidiano escolar.

Assim, a visita a nossas experiências profissionais anteriores não significa apenas recolher o que foi vivido para agitar os sentimentos da recordação, mas, sobretudo, pensar o que foi visto diante do que agora parece urgente e necessita de novos agenciamentos - práticas e pesquisas. Significa, portanto, raspar a matéria da memória com a emoção ativa de quem precisa desempenhar-se no cultivo da vida. Nossa inquietação: nas escolas, quais são os modos de fortalecimento da existência (PISSOLATO, 2007) dessa juventude periferizada, em face das contrariedades que sofrem? Contrariedades múltiplas, violências diversas. Como professores, nunca nos escapou à visão cotidiana o fato de que parte considerável de nossos alunos precisava driblar ou lutar contra coisas demais dentro da própria escola. Embora as inconveniências e dificuldades surjam inevitavelmente da própria vida, de suas trilhas e descaminhos, algo muito desproporcional a suas capacidades individuais bate em seus corpos, quando acuados pelo regime mundializado de acumulação de capital e contenção de suas expressões que a cidade impõe. O global e o local produzem um feixe agudo de privações e silenciamento.

Nossa experiência de professores, descontando os aspectos corriqueiros da carreira (ou da falta de um plano de carreira...) e das conhecidas aflições da escola pública nessas redes de ensino, nos permite dizer que, apesar de tudo, a escola não é um lugar infeliz. Não é porque os alunos fazem diariamente da escola um território de realizações e fabulações. A contrapelo, nela vivem. E a música, proibida, controlada ou ignorada, é parte constitutiva e marcante dessa presença na escola. Com ela produzem eventual al- 
teridade - o que acreditam e aquilo que repulsam, para ser visto e ouvido, compreendido ou mal compreendido, entre eles e em relação a todos: inspetores, professores e direção. Alunos com seus fones de ouvindo, estão espalhados pela escola, até na sala de aula. Ouvem de tudo. O funk, porém, tem privilégio. Se não é a música mais ouvida (nas escolas que conhecemos era), é a mais repelida pelo establishment escolar. Aluno/a ouvindo funk é o exemplar mais exato do não aluno - alguém que não deseja e dificilmente será educado. O que, entretanto, mira/fita/encara/sonda/examina o funk?

\section{FUNK-JUVENILIDADES}

O funk não constitui a trilha sonora exclusiva das escolas públicas "periferizadas". Não é por aí. Essa rapaziada e as moças ouvem de tudo. Muitos alunos, aliás, rejeitam o funk. Preferem, muitas vezes, a marca distintiva do rock pesado ou do hip hop. Ou, ainda, gostam, genericamente, da música pop nacional e internacional. Podem preferir também diferentes segmentos da música nacional. Muito frequentemente há um gosto temperado pela mistura. Mas o que vamos chamar aqui de funkificação das escolas reúne um acontecimento inegável: o caráter popular do funk. Funk é música popular, é preciso admitir. Mas como é próprio das juvenilidades, o funk não é só música, não é apenas audição. O funk relaciona diversas práticas sociais, tais como comunicação (mídias), estilos (roupas transadas), encantamentos (adornos), estéticas (aparências, aparecimentos), posturas corporais (poses), atitudes (modos de proceder), relacionamento (saudações e tratamento) e sociabilidades (comunitarismo); além de fazer girarem seus agenciamentos entre a física do lugar (o bairro, a "comunidade", o baile e os locais de encontro) e a química das produções econômicas (artistas, empresários e a indústria do entretenimento). O funkeiro, por assim dizer, é menos personalidade do que identidade coletiva. Como pessoa, é ponto de encontro de muitas ações e investimentos; portanto, é irredutível a uma personificação atribuída pelo tipo de música que ouve.

Tampouco o funk pode ser reduzido a um "comportamento juvenil das favelas e/ ou dos pobres". Em sua complexidade sociológica, o funk não pode ser convertido à expressão de uma subcultura juvenil, reificado como uma das muitas tribos urbanas. Em primeiro lugar, ele é o que é a partir de seus elementos mais ordinários, despersonalizados e dispersivos. Ao contrário do que deseja fazer crer a vigilância moral das mídias mais poderosas economicamente, de onde partem as vozes a ele mais reativas, o funk é poesia e música cosmopolita. Por isso adere. No entanto, exatamente em razão de sua origem popular, penetrante e influente, mas tensa em relação à segregação que existe no território da cidade e no espaço do simbólico, sua presença, percebida através da audição e de outros sinais identitários, constrange, ameaça e conflita. Mesmo sem se constituir como gosto musical absoluto nas escolas, o funk é perturbador porque exerce diligente crítica de seu cotidiano. Não é todo mundo que ouve, mas está em todos os lugares. Está no boné, no tênis, na calça, no caminhar ou no falar. Cantado, no aparelho de mp3 e até no celular, o funk se amplifica, fala em voz alta. Exatamente ali, onde o silêncio é uma das normas da convivência, o funk diverge em volume alto, repulsando as prá- 
ticas de contenção que a escola promove. Sua investidura não aparece apenas nas escolas de "periferia". Também nos grupos escolares mais privilegiados, o funk é aliado da desobediência e da crítica.

Em razão dos elementos que o emolduram, especialmente a própria música (os sons dançantes), as poesias das letras (com assuntos que tratam diretamente de aspectos da vida) e seu caráter sociável (a promoção de festas ou a simples companhia sempre requerida dos amigos), sua vivência reage às circunstâncias adversas da vida, derramando ânimo e fortaleza. Os dias difíceis são assim virados ("Rap do Salgueiro" - Claudinho e Buchecha), ${ }^{2}$ empenhados em fantasias, sonhos e desejos ("Nosso sonho" - Claudinho e Buchecha), mas nunca alienados da necessária leitura do que são e como vivem, ainda que taticamente municiados por ironia ("Som de preto" - Amilcka e Chocolate) e zombaria ("Feira de Acari" - Mc Batata), apropriadas à crítica mordaz, cortan-

2. Todos os funks citados foram capturados em http://funkmp3. net em 12/03/2010. te e popular. Às vezes são sérios ("Rap do Silva" - Mc Bob Rum) ou mais revoltosos ("Guerreiro" - Betinho e Duda do Borel), mas sempre comoventes porque tocantes no empenho de buscar a alegria ("Rap do Festival" - Mc Danda e Mc Tafarel) e promover a existência ("Meus direitos" - Cidinho e Doca) diante da aflição e das covardias que sofrem ("Rap da Felicidade" - Cidinho e Doca).

\section{VIDA-FUNK}

Deslindar e explorar as potencialidades estéticas presentes no cotidiano das culturas infanto-juvenis a favor de processos educacionais voltados para a efetiva justiça social implicam, sob muitos aspectos, criar novas formas de apreensão das produções juvenis. Seguramente, a criação de outras formas de perceber a vida demanda desapegos tanto no campo dos abrigos conceituais quanto no campo das afinidades estéticas. Eis então um dos muitos aspectos que marcam as dificuldades da educação contemporânea, espectro institucional de um tempo roto que sofre a inexatidão entre seu projeto fantasmagorizado e uma incompreensível e inoportuna efervescência. Os funks, o batidão e suas poesias, pretensamente domados (nos invólucros da cultura de massas e da industria cultural) ou queridos proibidos, por quem quer que seja (os "proibidões", produzidos e distribuídos através de planos artesanais, informais ou marginais: os "funks sensuais" e os funks narrativos do cotidiano dos soldados, dos líderes e dos agrupamentos do tráfico) são também constitutivos do cotidiano escolar, e a complexidade dos seus agenciamentos produz o que chamamos de funkificação das escolas. Os funks motivam a vida e nas escolas são fortalecedores da presença daqueles que ali são preteridos, expulsos do ideal iluminista de desenvolvimento, apuro e civilização (GENTILI, 1995).

A vida escolar que destacamos excede, em suas indômitas produções estéticas, os limites que a sociedade precisava acreditar fixos. A escola, como qualquer outra instituição, não resiste às sequelas da predação capitalista. Se esse avassalador movimento destroça e aniquila, produz descontroladamente linhas de fuga a sua própria ação maquínica. Inventar formas de disponibilidade à afetação do que a vida nas escolas engen- 
dra é, inequivocadamente, inventar outra escola ou, talvez, outra máquina desejante que ocupe sua vacuidade. Talvez, mais do que refazer a escola, urge esquecê-la. Pois a vaziez provocada pelo esquecimento pode revelar-se fecundidade ímpar para impensadas iniciativas, por via de que a beleza circule com toda potência e a vida seja respeitada onde e de que forma venha a vibrar. A vida é bela, eles dizem. Uma arqueologia que não quer escavação muito funda, mas simplesmente tatear, encontra não vestígios ou resquícios, mas fulgurantes nascimentos.

A preparação para a coletivização das benesses e, entre elas, a das belezas, é um dos mais cruciais desafios que a educação formal/imaginal enfrenta. E é no sentido de fortalecer e corroborar com os mais recentes investimentos nessa luta-criação que criamos esse trabalho. Trata-se ainda do resultado de intensas lutas, tanto as dos desafios da cotidianidade das escolas quanto as decorrentes das ciladas investigativas da produção de nossas pesquisas. Nosso ato de pesquisar revela-se mais norteado pela fruição das produções culturais e estéticas juvenis em suas fabulosas abrangências e diversidade do que por qualquer sujeição decorrente de adesões teóricas incondicionais...

\section{REFERÊNCIAS BIBLIOGRÁFICAS}

ALVES, Nilda e OLIVEIRA, Inês Barbosa. Uma história da contribuição dos estudos do cotidiano escolar no campo do currículo. In: LOPES, Alice Casimiro e MACEDO, Eizabeth (orgs.). Currículo: debates contemporâneos. São Paulo: Cortez, 2002.

BLANCHOT, Maurice. O livro por vir. São Paulo: Martins Fontes, 2005.

DIDI-HUBERMAN, George. O que vemos, o que nos olha. São Paulo: Editora 34, 1998.

GENTILI, Pablo (org.). Pedagogía da exclusão: crítica ao neoliberalismo em educação. Petrópolis: Vozes, 1995.

GIROUX, Henry A. Cruzando as fronteiras do discurso educacional: novas políticas em educação. Porto Alegre: ArtMed, 1999.

HEIDGGER, Martin. A caminho da linguagem. Petrópolis: Vozes, 2003.

PISSOLATO, Elizabeth. A duração da pessoa: mobilidade, parentesco e xamanismo mbya (guarani). São Paulo/Rio de Janeiro: Edunesp/ISA/NuTi, 2007.

Aldo Victorio Filho é graduado em Artes pela EBA/UFRJ, mestre e doutor em Educação pela Uerj, professor do lart/Uerj e do PPGartes/Uerj, pesquisador dos grupos de pesquisa Estudos Culturais em Educação e Arte, e Redes de Conhecimentos e Práticas Emancipatórias no Cotidiano Escolar.

Aristóteles de Paula Berino é graduado em História pela UFF, mestre e doutor em Educação pela UFF, pós-doutorado no Proped/Uerj, professor do IM/UFRRJ/Nova Iguaçu e do PPGEduc/UFRRJ, pesquisador dos grupos de pesquisa Estudos Culturais em Educação e Arte, e Currículo, Redes Educativas e Imagens, e do Leafro (Neabi/UFRRJ). 